\title{
Perancangan Sistem Informasi Absensi Siswa Berbasis Online di SMK Modellink Sorong
}

\author{
Fitri Febry Irianti ${ }^{1}$, Firman $^{2}$, Sahiruddin $^{3}$ \\ Pendidikan Teknologi Informasi \\ Universitas Pendidikan Muhammadiyah Sorong \\ Fitrifbry@gmail.com ${ }^{1}$, firmantajdiduliman@gmail.com ${ }^{2}$, sahiruddinbuton@ gmail.com ${ }^{3}$
}

\begin{abstract}
Abstrak: Penelitian ini bertujuan untuk mengetahui langkah-langkah penggunaan sistem informasi absensi siswa berbasis online di SMK Modellink Sorong dan perancangan sistem informasi absensi siswa berbasis online di SMK Modellink Sorong yang valid. penelitian ini menggunakan metode R\&D (Research and Development) dengan menggunakan tahapan : Mencari Potensi dan Masalah, pengumpulan data, desain produk, validasi produk, ujicoba pemakaian, revisi produk, ujicoba produk, revisi desain, revisi produk, dan produksi masal. Dalam penelitian ini yang menjadi subjek adalah siswa dan guru SMK Modellink Sorong. Berdasarkan hasil penelitian yang telah dilakukan didapatkan hasil berupa sistem informasi absensi dan perancangan buku panduan sistem absensi siswa berbasis online yang telah di lakukan ujicoba Black Box yang diujicobakan oleh validator ahli dan ujicoba kelompok besar 25 orang responden dengan persentase 92\% untuk aspek pengguna, 91\% untuk aspek navigasi, $90 \%$ untuk aspek praktis, $86 \%$ untuk aspek efektif dan $88 \%$ untuk buku panduan dengan hasil sangat baik sehingga sistem dapat digunakan. Penelitian ini menghasilkan sebuah sistem informasi absensi siswa berbasis online di SMK Modellink Sorong.
\end{abstract}

Kata Kunci: Absensi; R\&D; sistem informasi.

\section{Pendahuluan}

Perkembangan ilmu teknologi semakin berkembang pesat, salah satunya perkembangan Teknologi informasi dibidang Pendidikan, Melalui teknologi informasi berbagai informasi dapat diperoleh dengan cepat, pelayanan Pendidikan di sekolah negeri dan swasta mengalami perkembangan dan perbaikan sesuai era digital, Sistem informasi absensi yang dapat diakses secara real team, valid dan efektif.

Berdasarkan UU Nomor 20 Tahun 2003 Tentang Sistem Pendidikan Nasional Dalam UU ini penyelenggaraan pendidikan wajib memegang beberapa prinsip yakni pendidikan diselenggarakan secara demokratis dan berkeadilan serta tidak diskriminatif dengan menjunjung tinggi hak asasi manusia, nilai keagamaan, nilai kultural, dan kemajemukan bangsa dengan satu kesatuan yang sistemik dengan sistem terbuka dan multimakna,

SMK Modellink merupakan sekolah Swasta yang didirikan oleh Yayasan Mubarakah pada tahun 2005, yang berada di jalan Katapop KM.34 SP3 kelurahan Mayamuk, Distrik Makbusun Kabupaten Sorong, Provinsi Papua Barat. Memiliki 29 Guru dan 540 siswa yang terbagi menjadi 4 Jurusan (a) Teknik Komputer \& Jaringan (TKJ), (b) Akuntansi (AK), (c) Teknik Kendaraan Ringan (TKR), dan (d) Teknik Alat Berat (TAB).

\section{Metode Penelitian}

Jenis penelitian ini menggunakan pendekatan penelitian dan pengembangan (Research and Development/ $R \& D)$. $R \& D$ merupakan metode yang sangat cocok untuk sebuah 
penelitian bertujuan untuk menghasilkan sebuah produk. $R \& D$ telah banyak digunakan pada penelitian bidang teknik yang menghasilkan produk teknologi.

Tahap penelitian dalam perancangan sistem ini peneliti akan menggunakan model pengembangan waterfall. waterfall adalah model klasik yang bersifat sistematis, berurutan dalam membangun software.

a. Teknik Pengumpulan Data

Teknik pengumpulan data yang dugunakan dalam penelitian ini adalah dengan beberapa metode yaitu :

1. Wawancara

Wawancara dilakukan agar peneliti dapat mengumpulkan data-data yang berkaitan dengan masalah yang terjadi pada objek penelitian sekaligus mencari solusi dari permasalahan tersebut.

2. Kuesioner

Kuesioner merupakan Teknik pengumpulan data primer yang dilakukan dengan cara menyebarkan seperangkat daftar pertanyaan tertulis kepada responden yang menjadi subjek penelitian, yaitu Siswa dan Guru SMK Modellink Sorong. Tujuan dari kuesioner ini, untuk mengetahui dan mengukur aspek desain dan kelengkapan fitur dalam sistem informasi absensi siswa berbasis online. Instrumen yang digunakan pada penelitian ini adalah kuesioner skala likert digunakan untuk mengukur sikap, pendapat, dan persepsi seseorang atau sekelompok orang tentang fenomena sosial.

3. Studi Pustaka

Studi pustaka untuk melaksanakan penelitian ini di dapatkan dari buku-buku referensi, jurnal nasional serta informasi di internet yang relevan dan sesuai dengan kebutuhan peneliti.

4. Dokumentasi

Metode ini digunakan untuk mendapatkan data berupa dokumen sesuai dengan keadaan lapangan mengenai hal yang berkaitan dengan implementasi sistem informasi absensi siswa berbasis online .

b. Teknik Analisis Data

Menurut Sugiyono (2016:147) Metode analisis deskriptif adalah "Metode statistik yang digunakan untuk menganalisis data dengan cara mendeskriptifkan atau menggambarkan data yang telah terkumpul sebagaimana adanya tanpa bermaksud membuat kesimpulan yang berlaku umum atau generalisasi". Untuk menghitung persentase hasil observasi menggunakan rumus Persamaan.

$$
P=\frac{\text { skor hasil pengumpulan data }}{\text { skor ideal }} \times 100 \%
$$

Rumus Persamaan

Keterangan:

$\mathrm{P}=$ angka persentase

Skor ideal $=$ skor tertinggi $\mathrm{x}$ jumlah responden $\mathrm{x}$ jumlah butir.

Jenis analisis data tersebut diuraikan lebih rinci untuk menjawab setiap pertanyaan penelitian sebagai berikut:

1. Validitas

Kategori validitas setiap aspek atau keseluruhan aspek yang dinilai ditetapkan berdasarkan kriteria pengkategorian dengan kriteria pengkategorian pada Tabel 1 
Tabel 1 Kategori Validitas

\begin{tabular}{ccc}
\hline No & Interval & Kategori \\
\hline 1 & $76-100 \%$ & Sangat valid \\
2 & $56-75 \%$ & Valid \\
3 & $40-55 \%$ & Kurang valid \\
4 & Kurang dari $40 \%$ & Tidak valid \\
\hline
\end{tabular}

2. Praktis

Kategori penilaian praktis atau menilai kemudahan penggunaan sistem informasi absensi berbasis online yang dinilai berdasarkan kriteria pengkategorian pada Tabel 2

Tabel 2 Kategori Praktis

\begin{tabular}{lcl}
\hline No & Interval & Kategori \\
\hline 1 & $76-100 \%$ & Sangat praktis \\
2 & $56-75 \%$ & Praktis \\
3 & $40-55 \%$ & Kurang praktis \\
4 & Kurang dari $40 \%$ & Tidak praktis \\
\hline
\end{tabular}

3. Efektif

Kategori penilaian efektif atau menilai kemudahan penggunaan sistem informasi absensi berbasis online yang dinilai berdasarkan kriteria pengkategorian pada Tabel 3

Tabel 3 Kategori efektif

\begin{tabular}{lcl}
\hline No & Interval & Kategori \\
\hline 1 & $76-100 \%$ & Sangat efektif \\
2 & $56-75 \%$ & Efektif \\
3 & $40-55 \%$ & Kurang efektif \\
4 & Kurang dari $40 \%$ & Tidak efektif \\
\hline
\end{tabular}

\section{Hasil dan Pembahasan}

Hasil perancangan sistem informasi absensi siswa berbasis online di SMK Modellink Sorong menggunakan model pengembangan waterfall yang terdapat pada metode pengembangan $R \& D$ (Research and Development/ $R \& D$ ), meliputi Langkah analisis kebutuhan, Perencanaan, Melakukan perancangan, Melakukan pengkodean \& testing, Penyebaran produk.

Uji coba merupakan uji coba utama untuk mengukur kelayakan sistem informasi penerimaan mahasiswa baru yang dipergunakan dan diterapkan. Uji coba lapangan melibatkan 30 responden yang terdiri dari: 24 Mahasiswa, 1 Guru SMK Modelllink Sorong, dan 5 Siswa Modellink Sorong.

Uji coba terdiri dari 5 indikator yaitu: (1) Aspek Pengguna, (2) Navigasi, (3) penggunaan aplikasi (praktis), (4) penggunaan aplikasi (efektif), (5) Buku Manual. Pengujian ini dimaksudkan untuk mengukur bagaimana kualitas sistem informasi yang dihasilkan tidak lagi membahas masalah konten pada sistem sehingga dapat diketahui kehandalan dan manfaat sistem yang akan diterapkan.

1. Indikator Aspek Pengguna

Pada indikator ini ada 4 sub indikator untuk mengukur bagaimana kualitas sistem dalam penggunaannya. Penilaian dilakukan oleh 30 responden yang terdiri dari: 24 Mahasiswa, 1 Guru SMK Modelllink Sorong, dan 5 Siswa Modellink Sorong. 
berdasarkan sub indikator yaitu: (1) Aspek Pengguna, (2) Navigasi, (3) penggunaan aplikasi (praktis), (4) penggunaan aplikasi (efektif), (5) Buku Manual.

Rangkuman hasil evaluasi responden pada indikator aspek pengguna ditunjukan pada tabel 4. Hasil uji coba sub indikator (1) Mudah dipahami memperoleh rerata 3 dan presentase $75 \%$ berada pada kategori baik. Sub indikator (2) Mudah digunakan memperoleh rerata 3,4 dan presentase $85 \%$ berada pada kategori sangat baik. Sub indikator (3) Memudahkan dalam proses absensi siswa dengan rerata 3,4 dan presentase $85 \%$ berada pada kategori sangat baik. Sub indikator (4) Memudahkan dalam proses rekapan hasil absensi siswa dengan rerata 3,2 dan presentase $80 \%$ berada pada kategori sangat baik.

Tabel 4 Indikator Aspek Pengguna

\begin{tabular}{lllll}
\hline No & Indikator & Rerata & Presentase & Kesimpulan \\
\hline 1 & Mudah dipahami & 3 & $75 \%$ & Valid \\
2 & $\begin{array}{l}\text { Mudah digunakan } \\
\text { Memudahkan dalam proses }\end{array}$ & 3,4 & $85 \%$ & Sangat valid \\
3 & $\begin{array}{l}\text { absensi siswa } \\
\text { Memudahkan dalam proses } \\
4\end{array}$ & 3,4 & $85 \%$ & Sangat valid \\
rekapan hasil absensi siswa & 3,2 & $80 \%$ & Sangat valid \\
\hline & Keseluruhan indikator & $\mathbf{3 , 3}$ & $\mathbf{8 1 \%}$ & Sangat valid \\
\hline
\end{tabular}

Data indikator aspek pengguna yang ditunjukan pada tabel 4 diatas menunjukkan keseluruhan aspek pengguna memiliki rerata 3,3 dan persentase $81 \%$ berada dalam kategori sangat baik, dapat disimpulkan bahwa keseluruhan indikator aspek pengguna sudah dapat dikatan baik.

\section{Indikator Navigasi}

Pada indikator ini mengukur fungsi menu yang ada pada sistem informasi absensi siswa yang telah di ujicoba, Indikator ini terbagi dari 4 sub indikator yaitu : (1) kemudahan memilih menu (2) kemudahan penggunaan menu (3) ada peringatan jika melakukan kesalahan login atau input data (4) kemudahan input dan hapus data. Data dari hasil uji coba dapat dilihat pada Tabel 5

Tabel 5 Indikator Navigasi

\begin{tabular}{lllll}
\hline No & Indikator & Rerata & Presentase & Kesimpulan \\
\hline 1 & Kemudahan memilih menu & 3,4 & $85 \%$ & Sangat valid \\
2 & $\begin{array}{l}\text { Kemudahan penggunaan menu } \\
\text { Ada peringatan jika melakukan }\end{array}$ & 3,6 & $90 \%$ & Sangat valid \\
3 & $\begin{array}{l}\text { kesalahan login atau input data } \\
\text { Kemudahan input dan hapus }\end{array}$ & 3,4 & $85 \%$ & Sangat valid \\
4 & $\begin{array}{l}\text { data } \\
\text { Keseluruhan indikator }\end{array}$ & 3,4 & $85 \%$ & Sangat valid \\
\hline
\end{tabular}

Pada tabel 5 dapat digambarkan pada sub indikator (1) Kemudahan memilih menu dikategorikan sangat baik dengan nilai rerata 3,4 dan persentase $85 \%$, pada sub indikator (2) Kemudahan penggunaan menu dikategori sangat baik dengan nilai rerata 3,6 dan persentase 90\% hal ini menunjukkan kemudahan dalam memilih menu pada sistem sangat baik, sub indikator (3) Ada peringatan jika melakukan kesalahan login atau input data dikategorikan 
sangat baik dengan nilai rerata 3,4 dan persentase $85 \%$ hal ini menunjukkan dalam mengurangi kesalahan pengunaan sistem, sub indikator (4) Kemudahan input dan hapus data dikategorikan sangat baik dengan nilai rerata 3,4 dan persentase $85 \%$ Hal ini menunjukkan dalam proses penghapusan data sistem dapat berfungsi dengan sangat baik.

3. Indikator Penggunaan Aplikasi (praktis)

Pada indikator ini mengukur sistem informasi absensi siswa yang telah di ujicoba, indikator ini terbagi dari 4 sub indikator yaitu: (1) Penggunaan aplikasi secara bersamaan, (2) penggunaan aplikasi mengefisienkan waktu, (3) penggunaan aplikasi mengefisienkan tempat, (4) penggunaan aplikasi diberbagai hardware dan software yang ada. Data dari hasil ujicoba dapat dilihat pada tabel 6

Tabel 6 Indikator penggunaan aplikasi (praktis)

\begin{tabular}{lllll}
\hline No & Indikator & Rerata & Presentase & Kesimpulan \\
\hline 1 & $\begin{array}{l}\text { Penggunaan aplikasi secara } \\
\text { bersamaan }\end{array}$ & 3,4 & $85 \%$ & Sangat valid \\
2 & $\begin{array}{l}\text { Penggunaan aplikasi } \\
\text { mengefisienkan waktu }\end{array}$ & 3,8 & $95 \%$ & Sangat valid \\
3 & $\begin{array}{l}\text { Penggunaan aplikasi } \\
\text { mengefisienkan tempat } \\
\text { penggunaan aplikasi diberbagai } \\
\text { hardware dan software yang ada }\end{array}$ & 3,6 & $90 \%$ & Sangat valid \\
\hline & Keseluruhan indikator & $\mathbf{3 , 7}$ & $\mathbf{9 1 \%}$ & Sangat valid \\
\hline
\end{tabular}

Tabel 6 dapat digambarkan pada sub indikator (1) Penggunaan aplikasi secara bersamaan dikategorikan sangat baik dengan nilai rerata 3,4 dan persentase $85 \%$, pada sub indikator (2) Penggunaan aplikasi mengefisienkan waktu dikategori sangat baik dengan nilai rerata 3,8 dan persentase 95\%. Sub indikator (3) Penggunaan aplikasi mengefisienkan tempat dikategorikan sangat baik dengan nilai rerata 3,6 dan persentase 90\%. Sub indikator (4) penggunaan aplikasi diberbagai hardware dan software yang ada dikategori sangat baik dengan nilai rerata 3,8 dan persentase $95 \%$. Hal ini menunjukkan penggunaan aplikasi tidak memerlukan spesifikasi khusus untuk di diterapkan dan digunakan.

4. Indikator Penggunaan Aplikasi (efektif)

Indikator ini mengukur sistem informasi absensi siswa yang telah di ujicoba, indikator ini terbagi dari 3 sub indikator yaitu: (1) Inputan/masukan aplikasi sesuai dengan output/keluaran, (2) Tidak terjadi kesalahan (error) pada saat aplikasi dijalankan, (3) penginputan atau data yang dimasukan diproses (terselesaikan). Data dari hasil ujicoba dapat dilihat pada tabel 7

Tabel 7 Indikator penggunaan aplikasi (efektif)

\begin{tabular}{lllll}
\hline No & Indikator & Rerata & Presentase & Kesimpulan \\
\hline 1 & $\begin{array}{l}\text { Inputan/masukan aplikasi sesuai } \\
\text { dengan output/keluaran }\end{array}$ & 3,4 & $85 \%$ & Sangat valid \\
2 & $\begin{array}{l}\text { Tidak terjadi kesalahan (error) } \\
\text { pada saat aplikasi dijalankan } \\
\text { penginputan atau data yang } \\
\text { dimasukan diproses (terselesaikan) }\end{array}$ & 3,8 & $95 \%$ & Sangat valid \\
\hline & Keseluruhan indikator & $\mathbf{3 , 7}$ & $\mathbf{9 2 \%}$ & Sangat valid \\
\hline
\end{tabular}


Table 7 dapat digambarkan pada sub indikator (1) Inputan/masukan aplikasi sesuai dengan output/keluaran dikategorikan sangat baik dengan nilai rerata 3,4 dan persentase $85 \%$, pada sub indikator (2) Tidak terjadi kesalahan (error) pada saat aplikasi dijalankan dikategorikan sangat baik dengan nilai rerata 3,8\% dan persentase 95\%, pada sub indikator (3) penginputan atau data yang dimasukan diproses (terselesaikan) dikategorikan sangat baik dengan nilai rerata $3,8 \%$ dan persentase $95 \%$. Hal ini menunjukkan bahwa sistem informasi absensi siswa mampu menerima masukan dan melakukan pemrosesan data dengan baik.

\section{Buku Manual}

Indikator buku manual ini mengukur tingkat kemudahan dalam menggunakan sistem informasi absensi siswa. Uji coba dilakukan kepada 30 responden. Indikator kepuasan terdiri dari 3 sub indikator yaitu: (1) Buku petunjuk penggunaan menarik dan mudah dipahami, (2) Bahasa buku petunjuk singkat dan jelas, (3) buku petunjuk penggunaan mudah digunakan. Data dari hasil ujicoba dapat dilihat pada tabel 8.

Tabel 8 Buku Manual

\begin{tabular}{lllll}
\hline No & Indikator & Rerata & Presentase & Kesimpulan \\
\hline 1 & $\begin{array}{l}\text { Buku petunjuk penggunaan } \\
\text { menarik dan mudah dipahami }\end{array}$ & 3,2 & $80 \%$ & Sangat valid \\
2 & $\begin{array}{l}\text { Bahasa buku petunjuk singkat } \\
\text { dan jelas }\end{array}$ & 3,8 & $95 \%$ & Sangat valid \\
3 & $\begin{array}{l}\text { buku petunjuk penggunaan } \\
\text { mudah digunakan }\end{array}$ & 3,6 & $90 \%$ & Sangat valid \\
\hline
\end{tabular}

Table 8 dapat digambarkan pada sub indikator (1) Buku petunjuk penggunaan menarik dan mudah dipahami dikategorikan sangat baik dengan nilai rerata 3,2 dan persentase $80 \%$, (2) Bahasa buku petunjuk singkat dan jelas dikategorikan sangat baik dengan nilai rerata 3,8 dan persentase $95 \%$, (3) buku petunjuk penggunaan mudah digunakan dikategorikan sangat baik dengan nilai rerata 3,6 dan persentase $90 \%$. Hal ini menunjukkan tingkat kemudahan dalam mengakses sistem informasi absensi siswa sangat baik.

\section{Kesimpulan dan Saran}

Berdasarkan hasil Penelitian dan Perancangan Sistem Informasi Absensi Siswa Berbasis Online pada SMK Modellink Sorong dengan menggunakan metode RnD dapat disimpulkan bahwa penulis berhasil merancang sistem informasi absensi siswa berbasis online pada SMK Modellink sorong dengan baik. Sistem informasi absensi siswa berbasis online pada SMK Modellink sorong juga sudah memiliki panduan berupa manual book dalam penggunaannya yang dimana dibuat oleh penulis untuk memudahkan pengguna dalam mengoprasikan sistem tersebut dengan presentase buku manual yaitu $85 \%$ dari hasil ujicoba kelompok kecil dan $88 \%$ dari hasil ujicoba kelompok besar dengan hasil sangat baik.

Sistem yang telah dibuat memiliki penilaian cukup baik dari validator ahli dengan presentase 92\% untuk aspek program, 86\% untuk aspek tampilan dan 82\% untuk aspek pengguna dan masuk dalam kategori sangat baik, dalam pengujian uji coba blackbox untuk mengukur kevalidan sistem absensi siswa maka telah sesuai dengan hasil pengujian, dengan hasil yang telah dicapai Sistem Absensi Siswa Berbasis Online pada SMK Modellink Sorong telah memenuhi harapan dan layak untuk digunakan. 
Sistem informasi absensi dalam pelaksanaan penelitian ini, maka penulis memberikan saran-saran yaitu: Bagi peneliti selanjutnya yang ingin mengembangkan Sistem Informasi Absensi Siswa Berbasis Online pada SMK Modellink Sorong agar dapat membuat sistem yang lebih kompleks dengan menambahkan beberapa fitur dan item yang masih belum berfungsi dengan baik. Untuk menu rekapan bisa menambahkan data rekap setiap bulan dan semester dan bisa membuat cetak absensi sesuai dengan rekapan absensi.

\section{Daftar Pustaka}

Apriliani, D., \& Somantri, O. (2015). Integrasi Fitur Back-End Untuk Pengembangan Sistem Informasi. Jurnal Teknologi Informasi Dan Komunikasi (JTIK) STMIK ProVisi Semarang, (2014), 21-27.

Ayu, F., \& Permatasari, N. (2018). Perancangan Sistem Informasi Pengolahan Data Praktek Kerja Lapangan (Pkl) Pada Devisi Humas Pt. Pegadaian. Intra-Tech, 2(2), 12-26.

Destiningrum, M., \& Adrian, Q. J. (2017). Sistem Informasi Penjadwalan Dokter Berbassis Web Dengan Menggunakan Framework Codeigniter (Studi Kasus: Rumah Sakit Yukum Medical Centre). Jurnal Teknoinfo, 11(2), 30-37. Retrieved from https://ejurnal.teknokrat.ac.id

dwi lestari. (2018). Bab ii tinjauan pustaka 2.1. 5-22.

Eka Iswandy. (2015). Sistem Penunjang Keputusan Untuk Menentukan Dan Santunan Sosial Anak Nagari Dan Penyaluran Bagi Mahasiswa Dan Pelajar Kurang Mampu. Jurnal TEKNOIF, 3(2). https://doi.org/2338-2724

Eko Budi Setiawan, B. K. (2015). Perancangan Sistem Absensi Kehadiran Perkuliahan dengan Menggunakan Radio Frequency Identification ( RFId ). 1(2), 44-49.

Firliana, R., \& Rhohman, F. (2019). Aplikasi Sistem Informasi Absensi Mahasiswa dan Dosen. Journal of Computer and Information Technology, 2(2), 70-74. https://doi.org/10.25273/DOUBLECLICK.V2I2.3921

Husain, A., Prastian, A. H. A., \& Ramadhan, A. (2017). Perancangan Sistem Absensi Online Menggunakan Android Guna Mempercepat Proses Kehadiran Karyawan Pada PT. Sintech Berkah Abadi. Technomedia Journal, 2(1), 105-116. https://doi.org/10.33050/tmj.v2i1.319

Istiono, W., Hijrah, H., \& Sutarya, S. (2016). Pengembangan Sistem Aplikasi Penilaian dengan Pendekatan MVC dan Menggunakan Bahasa PHP dengan Framework Codeigniter dan Database MYSQL pada Pahoa College Indonesia. Jurnal TICOM, 5(1), 53-59. Retrieved from https://media.neliti.com/media/publications/93757-IDpengembangan-sistem-aplikasi-penilaian-d.pdf

Juardi, D. (2019). Presensi dan Reminder menggunakan QR Code (Studi Kasus: SMA XXX). Systematics, 1(1), 33. https://doi.org/10.35706/sys.v1i1.2011

M. Ilham Sugiarto, Arie Linarta, A. S. (2019). Aplikasi Layanan Informasi Absen Dan Nilai Berbasis Sms Gayeway Menggunakan Php Pada Smk Taruna Persada Dumai. I N F O R M a T I K A, 9(2), 60. https://doi.org/10.36723/juri.v9i2.106

Mursid, M. E. (2016). Sistem Informasi Kesiswaan Berbasis Web Pada Smk

Negeri 1 Rarowatu Kab.Bombana. 1(1), 29-37. 
Muslihudin, M., Krisdianto, R., \& Nanda, A. P. (2018). Sistem Aplikasi Data Absensi Pada SMK Negeri 1 Talang Padang Menggunakan Model SMS Gateway Sebagai Layanan Informasi Wali Murid. Jurnal Management Sistem Informasi Dan Teknologi, 08(02), 61-66. https://doi.org/10.1017/CBO9781107415324.004

Nurcahyo, S. (2016). Analisis Pengembangan Sistem Informasi Geografis Untuk Pemetaan Perguruan Tinggi Di Yogyakarta. Jurnal Pendidikan Teknik Informatika, 934(2), 1-8.

Pande Putu Gede Putra Pertama. (2019). Digital Informasi Kehadiran Status Dosen ITB STIKOM Bali Berbasis Web. RESEARCH: Computer, Information System \& Technology Management, 2(2), 64. https://doi.org/10.25273/research.v2i02.5223

Panjaitan, A., Amren, H., Nasution, D., Khair, R., \& Idris, I. (2020). Sistem Monitoring Evaluasi Dan Pelaporan Kegiatan Taruna Atkp Medan. REMIK (Riset Dan E-Jurnal Manajemen Informatika Komputer), 4(2), 82. https://doi.org/10.33395/remik.v4i2.10561

Putra, G. P., Santoso, N., Muhammad, E., \& Junemaro, A. (2019). Rancang Bangun Sistem Informasi Manajemen Persuratan Dinas Pendidikan Banyuwangi (Vol. 3).

Recky T. Djaelangkara, Rizal Sengkey, ST., MT, Oktavian A. LAntang, ST, M. (2015). Perancangan Sistem Informasi Akademik Sekolah Berbasis Web Studi Kasus Sekolah Menengah Atas Kristen 1 Tomohon. 86-94.

Rotikan, R. (2016). Sistem Informasi Absensi Berbasis Web Untuk Kegiatan Konferensi. Sisfotenika, 6(1), 46-55. https://doi.org/10.30700/jst.v6i1.104

Santoso, H., \& Yulianto, A. W. (2017). Analisa Dan Perancangan Sistem Absensi Siswa Berbasis Web Dan Sms Gateway. Jurnal Matrik, 16(2), 65. https://doi.org/10.30812/matrik.v16i2.11

Supramana, Prismana, I. G. L. P. E. (2016). Implementasi Load Balancing Pada Web Server Dengan Menggunakan Apache. Jurnal Manajemen Informatika, 5, 117-125.

Susanti, M. (2016). Perancangan Sistem Informasi Akademik Berbasis Web Pada Smk Pasar Minggu Jakarta. Informatika, 3(1), 91-99.

Swara, G. Y., Kom, M., \& Pebriadi, Y. (2016). Rekayasa Perangkat Lunak Pemesanan Tiket Bioskop Berbasis Web. Jurnal TEKNOIF, 4(2), 27-39.

Tidar, E., Utama, H., Wijaya, I. D., Retno, A., \& Hayati, T. (2015). Rancang Bangun Sistem Informasi Akademik Siswa Dengan Menggunakan Notifikasi Sms Pada Smk Muhammadiyah 1 Kepanjen. 18-24.

Wajidi, F. (2014). Sistem Digitalisasi Absensi Mahasiswa STMIK U'Budiyah Indonesia.

Widyanti, F. (2018). Sistem Informasi Penilaian Sikap Karyawan Berbasis Web. 4, 382-391.

Zebua, T., \& Pritiwanto. (2017). Pembangunan Web Mobile Absensi Mahasiswa Pada Platform Android Yang Terintegrasi Dengan Website Utama Sistem Informasi Akademik (SIA) STMIK Budi Darma. Jurnal Teknik Informatika Unika St. Thomas (JTIUST), 2(1), 100-107. 